\title{
Estudo de relevo e potencial de uso do solo no município de São João - Pernambuco
}

Study of relief and land use potential in the municipality of São João - Pernambuco

\section{Mário Melquiades Silva dos Anjos ${ }^{1}$, Sandrine Maria da Silva ${ }^{2}$, Anderson Santos da Silva ${ }^{3}$, Pâmela Rodrigues Azevedo ${ }^{4}$, Alan Cézar Bezerra ${ }^{5}$}

DOI: https://doi.og/10.52719/bjas.v3i1.4004

\section{RESUMO}

O objetivo do trabalho atual foi demonstrar o potencial de uso do solo no município de São João - Pernambuco, um dos maiores produtores de mandioca (Manihot esculenta) e maior produtor de feijão (Phaseolus vulgaris) do estado, sendo de grande importância econômica, em função de sua capacidade de desenvolvimento agrícola a partir de suas características de topografia. De posse de um software livre de elaboração de mapas, o QGIS, trabalhou-se os dados de imagens de satélite SRTM, a fim de descrever o perfil topográfico da região. A partir da análise de declividade do município, que se demonstrou, em sua maior extensão, ser Suave Ondulado (3-8\% de declividade) com 10.666,86 ha e Ondulado (8-20\% de declividade) com 9.566 ha, observou-se que as áreas com essa classificação possui elevado potencial produtivo para a implantação de espécies cultivadas, favorecendo tratos culturais, correlacionando com as informações de solo (predominantemente Latossolos e Neossolos Regolíticos) e clima (Tropical chuvoso com verão seco).

Palavras-chave: Declividade. QGIS. Software livre. Topografia.

\begin{abstract}
The objective of the current work was to demonstrate the potential of land use in the city of São João - Pernambuco, one of the largest producers of cassava (Manihot esculenta) and largest producer of beans (Phaseolus vulgaris) in the state, being of great economic importance, in function of its agricultural development capacity based on its topographic characteristics. With a free software for the elaboration of maps, the QGIS, the data from SRTM satellite images were worked on, in order to describe the topographic profile of the region. From the analysis of the slope of the municipality, which was shown, to its greatest extent, to be Suave Ondulado (3-8\% slope) with 10,666.86 ha and Ondulado (8-20\% slope) with 9,566 ha, It is noted that areas with this classification have high productive potential for the implantation of cultivated species, favoring cultural treatments, correlating with soil information (predominantly Latosols and Regolithic Neosols) and climate (rainy tropical with dry summer).
\end{abstract}

Keywords: Declivity. QGIS. Free software. Topography.

\footnotetext{
${ }^{1}$ Universidade Federal do Agreste de Pernambuco

${ }^{2}$ Autarquia de Ensino Superior de Garanhuns - AESGA

${ }^{3}$ Universidade Federal do Agreste de Pernambuco

${ }^{4}$ Universidade Federal do Agreste de Pernambuco

${ }^{5}$ Universidade Federal Rural de Pernambuco, Unidade Acadêmica de Serra Talhada
} 


\section{INTRODUÇÃO}

Em nossa sociedade é comum e tradicional que as práticas agrícolas sejam realizadas sem planejamento, em muitos casos, se utilizando de repetidas metodologias arcaicas e com pouca informação. Esta forma de manejo traz problemas ambientais e, portanto, para um manejo sustentável, o uso do solo na agricultura deve ser feito de maneira planejada.

O estudo do relevo é um dos fatores determinantes nesse planejamento, pois dita trajetória do recurso hídrico, indica zonas inagricultáveis por acentuada declividade, e demarca áreas de preservação, como os topos de morro, que segundo legislação brasileira (Conama n⿳⺈ 303/2002) se tornam APP's (Áreas de Preservação Permanente) para manutenção das áreas de recarga nas bacias hidrográficas. Portanto, é indispensável o levantamento do perfil topográfico local para elaboração de planejamento de uso e ocupação do solo. (Bergamo \& Almeida, 2006)

O planejamento para implantação das culturas agrícolas leva em consideração os fatores inerentes a cultura e do ambiente onde se desenvolve. Para obtenção das melhores respostas de colheita é necessário conhecer e interligar as informações de ambos seguimentos, analisando qual cultivar possui maior adaptação às condições edafoclimáticas locais e o que o ambiente pode oferecer a esta cultivar, bem como de sua capacidade de viabilizar práticas culturais, sejam mecanizadas ou de forma manual.

O relevo tem papel fundamental, onde quanto mais plano melhor são as condições de desenvolvimento e condução da cultura, pois apresenta maior facilidade às práticas culturais, tanto no uso de tratores e implementos (Höfig, 2015), como para plantio, colheita, irrigação ou atividades de controle de pragas e doenças, entre outras, habituais na condução da cultura, onde em relevos acentuados, além do risco de vida aos trabalhadores, torna-se impossível o uso de maquinário. (Malinovskiet et al., 2006)

Para tal estudo dispomos de várias ferramentas da tecnologia, que são atualizadas frequentemente seguindo a crescente demanda por informação. O uso de imagens de satélite ou de drones para descrição de áreas por meio de softwares, como o QGIS, é uma ferramenta poderosa para manipulação dos dados obtidos em campo, culminando em mapas e projeções gráficas da superfície da área a ser estudada.

Este trabalho de pesquisa tem o objetivo de demonstrar o potencial de uso do solo do município de São João, a partir do estudo do perfil topográfico e correlação com solo e clima, oferecendo informação e subsídio para planejamento de atividades agrícolas no local. 


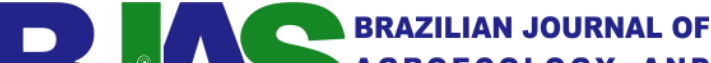 \\ AGROECOLOGY AND \\ SUSTAINABILITY}

\section{MATERIAL E MÉTODOS}

\subsection{Caracterização da área de estudo}

A área de estudo deste trabalho foi o município de São João - Pernambuco (Figura 1), Lat $08^{\circ} 52$ ' 33' 'S e Long 36 22' 01' 'W, altitude 716m (Prefeitura de São João-PE, 2017), com clima tropical chuvoso e verão seco, classificado Aw segundo Köppen, solos predominantemente Latossolos e Neossolos Regolíticos (Embrapa/Solos, 2000) e área de 26.397,366 ha. (Instituto Brasileiro de Geográfia e Estatistica - [IBGE], 2016).

\section{Figura 1.}

Mapa de localização do município de São João - PE

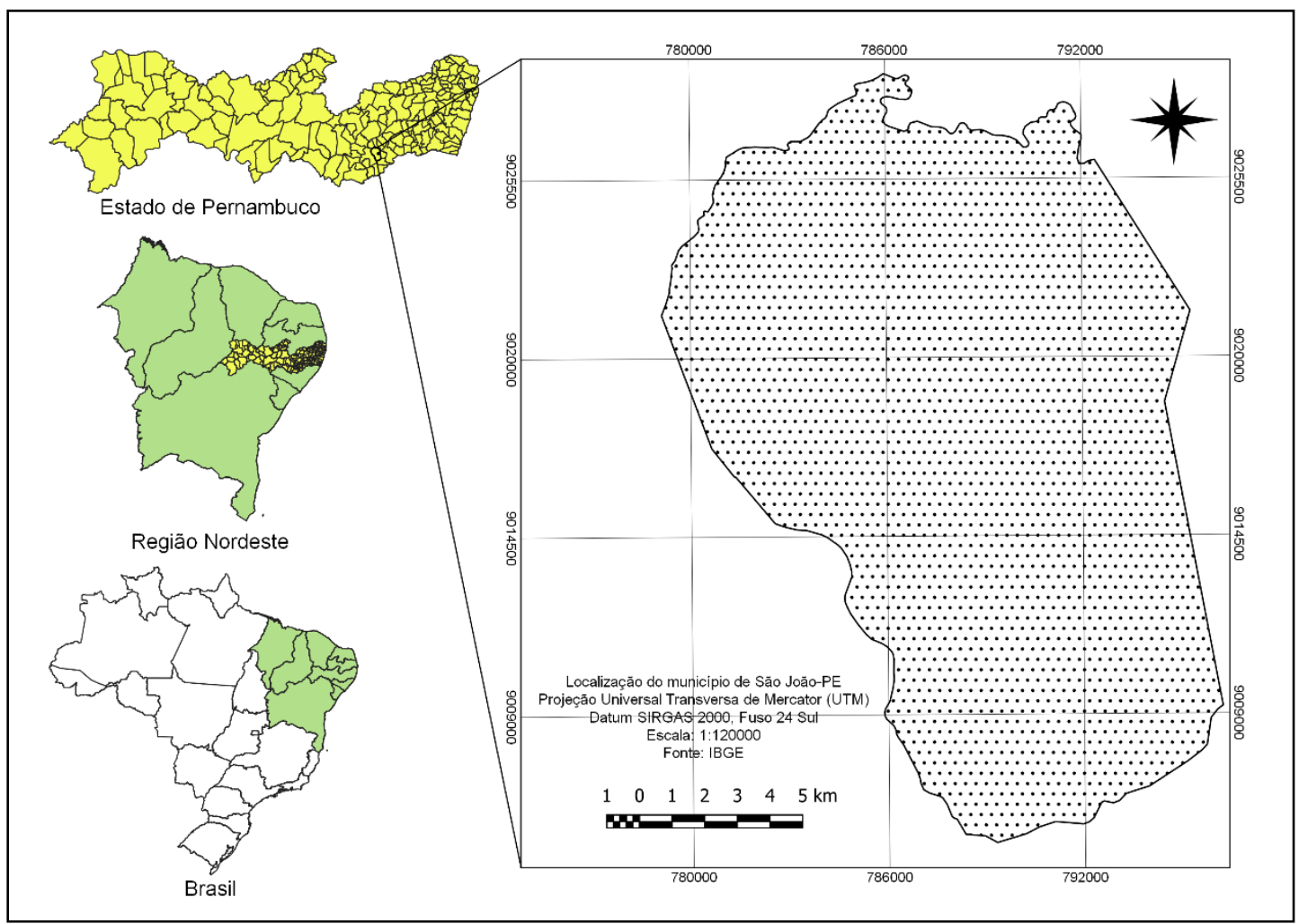

Fonte: Elaborado pelos Autores

O município encontra-se inserido na Bacia Hidrográfica do Rio Mundaú, e de acordo com Gomes et al. (2016), essa bacia hidrográfica apresenta características físicas diferenciadas ao longo de toda sua área. As nascentes do rio principal nascem em região semiárida, precisamente no alto do Planalto da Borborema e seu canal principal percorre cerca de $195 \mathrm{~km}$ das nascentes até seu exutório, passando por regiões de Caatinga, Agreste, Mata Atlântica e 
Litoral (Silva, 2018).

Segundo Gomes et al. (2016), as principais estruturas geológicas que formam a bacia são: Planalto da Borborema; Depressão Periférica da Borborema e Depósitos Sedimentares do período Quartanário.

\subsection{Procedimentos metodológicos}

Neste trabalho compreende o uso de imagens de Modelos Digitais de Elevação (MDE) através da utilização de dados altimétricos da missão Shuttle Radar Topographic Mission (SRTM), obtidas do Banco de Dados Geomorfométricos do Brasil - INPE (Instituto Nacional de Pesquisas Espaciais), disponíveis no site do TOPODATA, desenvolvidos por de Morisson Valeriano e de Fátima Rossetti (2012).

Essa imagem apresenta uma resolução espacial com pixel de 30 x 30 metros, ou seja, um pixel cobre uma área de $900 \mathrm{~m}^{2}$, aproximadamente. Em seguida, a imagem foi reprojetada para o hemisfério sul com o Datum SIRGAS 2000 e Sistema de Referencia de Coordenadas (SRC) Planas (UTM) no Fuso 24 Sul, compatíveis com o arquivo Shapefile da camada delimitadora do município, em seguida foi feito o recorte da área do município e todo o processamento digital da imagem no software livre QGIS versão L.T.R. 3.10.7.

O cálculo da declividade e classificação do relevo foi de suma importância para saber a aptidão agrícola e trajetória de natural no solo da precipitação pluviométrica e assim não comprometer através da agricultura na erodibilidade do terreno, essa metodologia obedeceu a proposta da Empresa Brasileira de Pesquisas Agropecuárias (EMBRAPA), conforme ilustra a Tabela 01.

Tabela 01 .

Classes de Classificação do relevo em função das declividades.

\begin{tabular}{cc}
\hline Classes de declividades & Limites percentuais (\%) \\
\hline Plano & $0-3$ \\
\hline Suave Ondulado & $3-8$ \\
\hline Ondulado & $8-20$ \\
\hline Forte Ondulado & $20-45$ \\
\hline Montanhoso & $45-75$ \\
\hline Escarpado & $>75$ \\
\hline
\end{tabular}

Fonte: EMBRAPA, 1979. 

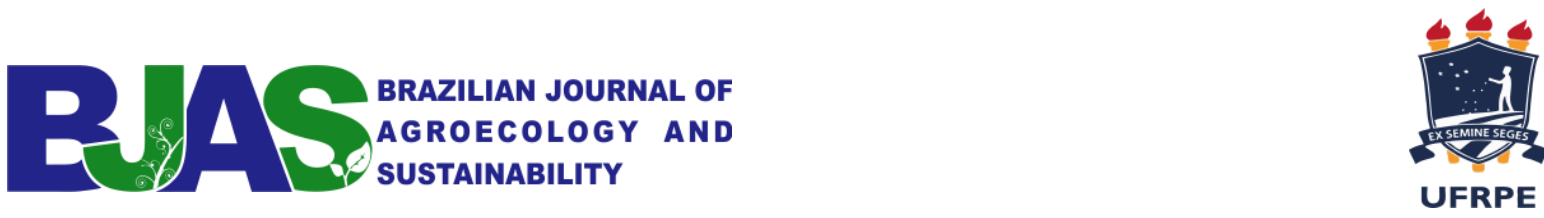

Para elaboração do mapa temático foi utilizado a metodologia de Barberi et al. (2012).

Nessa metodologia estão descritas as instruções para obtenção das imagens e seu processo de composição onde o software projeta as categorizações do relevo resultando no mapa apresentado nos resultados, assim como as classificações desde Plano à Montanhoso. Com o mesmo software também foi possível calcular as áreas pertencentes a cada classificação, posteriormente transformado em porcentagem para melhor apresentação e entendimento do contexto topográfico. Os mapas temáticos foram elaborados no compositor de impressão do software livre QGIS e assim demonstrar topograficamente o município.

\section{RESULTADOS E DISCUSSÃO}

\subsection{Declividade}

Na Figura 2 A encontra o MDE em cor natural e original delimitado para o município de São João-PE e na Figura 2B o mesmo MDE com aplicação de uma hipsometria de falsa-cor para destacar os valores altimétricos compreendidos no município. É possível observar na Figura 2, que a altitude está variando entre $611,52 \mathrm{~m}$ e 939,45 m nas cores do verde ao vermelho, respectivamente, diferenciando da altitude mínima até a máxima compreendida.

\section{Figura 2.}

Mapa com os valores altimétrico (em metros) original em A e com aplicação de falsa-cor em B para o município de São João-PE. 


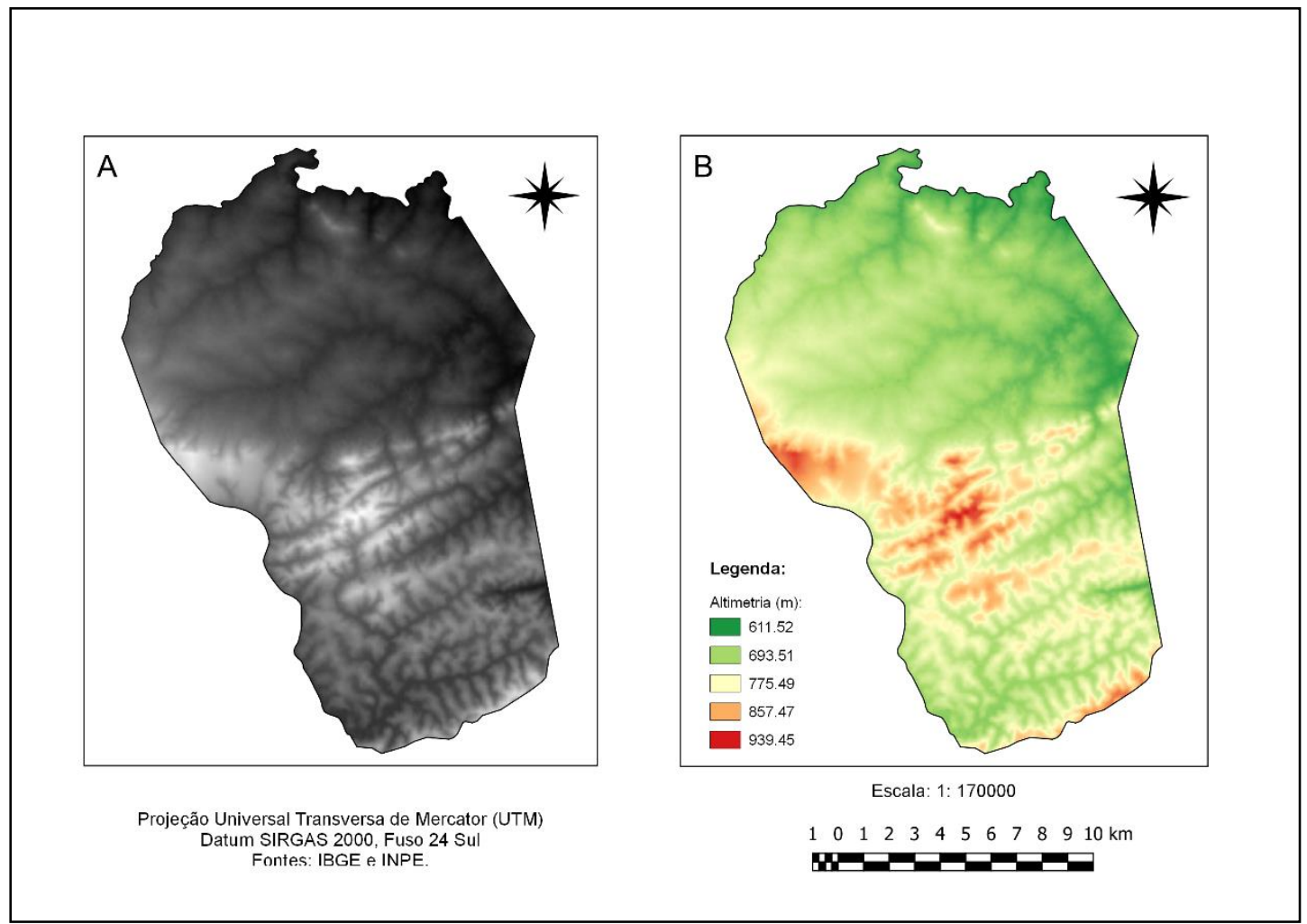

Fonte: Elaborado pelos Autores

A partir dos resultados obtidos através da manipulação dos dados no software livre (Figura 3), observou-se que a área é predominantemente Suave Ondulada com $40 \%$ da área, em seguida apresenta 36\% Ondulado, 15\% Forte Ondulado, 8\% Plano e por fim 0,2\% Montanhoso segundo a classificação da Embrapa (1979), demonstrando alto potencial agrícola por possuir relevo que possibilita instituição dessas atividades, mostrando-se favorável a mecanização e irrigação por gotejo, corroborando a Silveira et al. (2015). 
Figura 3.

Mapa de declividade em porcentagem (A) e da Classificação do Relevo (B) do município de São João-PE.

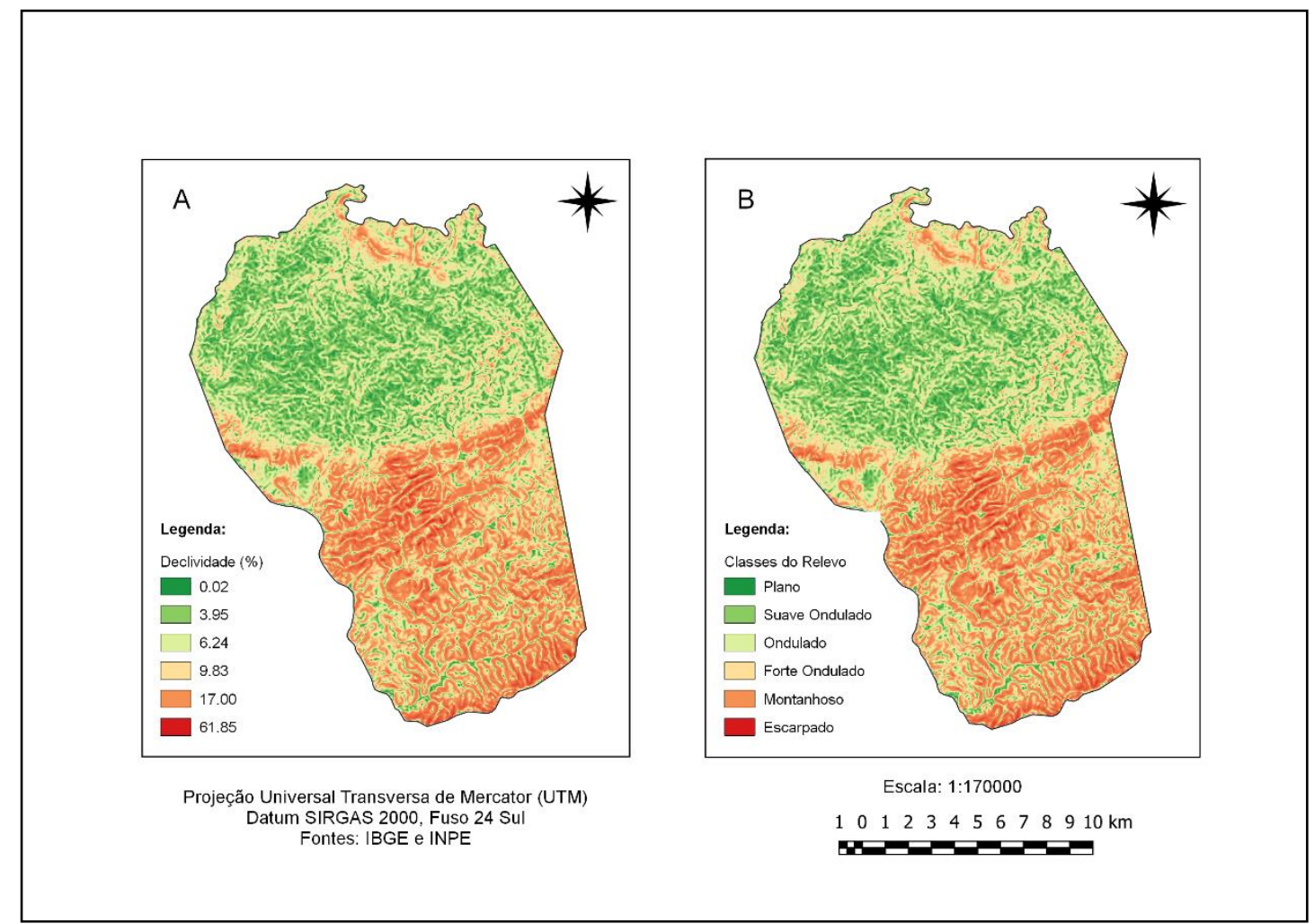

Fonte: Elaborado pelos Autores

A declividade do terreno é um fator importante no uso de uma irrigação mais eficiente. De acordo Andrade e Brito (2006), método de irrigação por superfície é ideal para regiões com até $15 \%$ de declividade, método por aspersão até $30 \%$ e gotejamento até $60 \%$.

$\mathrm{Na}$ Tabela 2, ilustra a distribuição das áreas em hectares de acordo com as classes de declividades (\%) em função de suas respectivas classificações semelhantes às encontradas na Figura 3 citada anteriormente.

\section{Tabela 2.}

Áreas correspondentes à classificação do relevo do munícipio de São João-PE.

\section{Distribuição das classes do relevo encontradas no município de São João-PE}

\begin{tabular}{ccc}
\hline Declividade & Área (ha) & Classificação do relevo \\
\hline $0-6 \%$ & $2.220,182$ & Plano \\
\hline $3-8 \%$ & $10.666,861$ & Suave Ondulado \\
\hline $8-20 \%$ & $9.566,002$ & Ondulado \\
\hline
\end{tabular}




\begin{tabular}{ccc}
\hline $20-45 \%$ & $3.885,677$ & Forte Ondulado \\
\hline $45-75 \%$ & 58,645 & Montanhoso \\
\hline$>75 \%$ & - & Forte Montanhoso \\
\hline
\end{tabular}

Total: $26.397,366$

Fonte: Elaborado pelos Autores

Segundo a Tabela 2, a declivdade é de suma importância, pois influencia diretamente no fluxo natural da água e, consequentemente, no processo erosivo, sombreamento, energia solar recebida, reflectância da superfície, temperatura, entre outras variáveis (Minella \& Merten, 2012).

\subsection{Aspecto do relevo}

Essa análise está diretamente ligada a orientação da declividade do terreno no que diz respeito aos caminhos naturais e sua contagem se dá a partir do norte $\left(0^{\circ}\right)$ e avança em sentido anti-horário culminando sua orientação oeste em $90^{\circ}$, a sua em $180^{\circ}$ e no leste $270^{\circ}$ segundo Bossle (2015).

Na Figura 4A encontra-se o aspecto do terreno em condição natural e em 4B, depois de uma renderização de cores, foi possível observar a variabilidade em graus no terreno e a orientação da declividade. O município apresenta boa parte de seu relevo classificado de plano a suave ondulado, em torno de $47,84 \%$, dificultando a distinção de orientações declivosas abruptas. Com menores declividades, pode-se desenvolver explorações agrícolas de forma mais favorável a conservação do solo. Quando o relevo apresenta alta declividade, ocorre em alguns casos a inviabilização da mecanização agrícola e limitações das técnicas de irrigação. Faz-se necessário a utilização de técnicas de conservação para reduzir a velocidade de escoamento superficial e proteger o solo. 

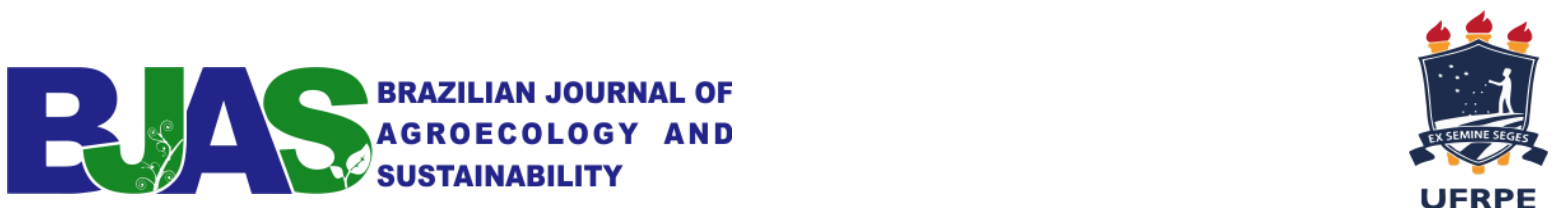

\section{Figura 4.}

Mapas de aspecto ou oriantação da dclividade com os valores em graus, original em A e com aplicação de falsa-cor em B para o município de São João-PE.

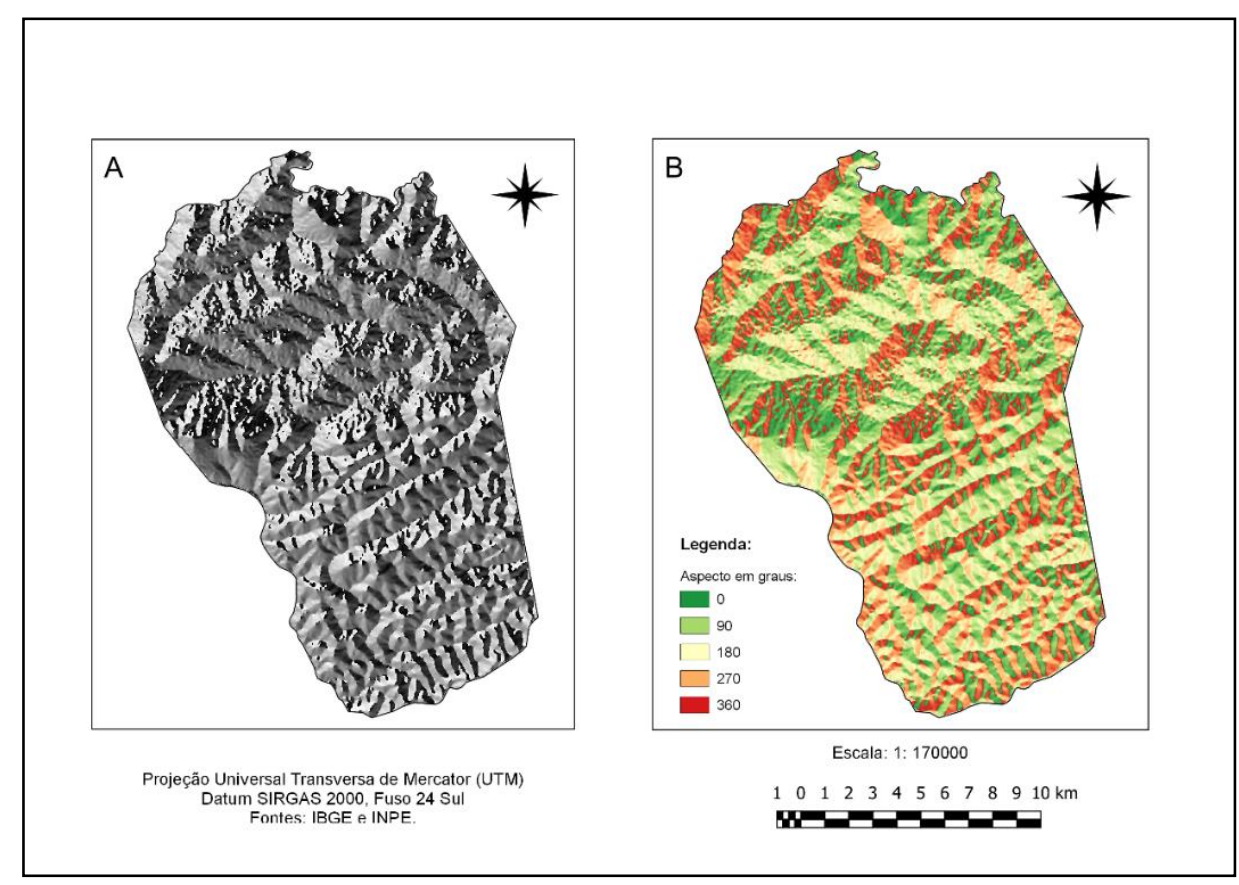

Fonte: Elaborado pelos Autores

\subsection{Sombreamento do relevo}

De acordo com Bossle (2015), o sombreamento permitiu a observação do relevo a partir da simulação de um foco reflectante com um ângulo de inclinação e azimute definidos. É muito utilizado para realçar o relevo dando uma visão bem detalhada.

Na Figura 5A encontra-se o sombreamento do terreno em condição natural e em 5B, depois de uma renderização de cores, foi possível destacar a variabilidade em graus no terreno mas pouco perceptível as calhas naturais e os seus divisores de água em função da grande porção do relevo apresentar características planas a suave onduladas. 


\section{Figura 5.}

Mapas do sombreamento com os valores em graus, original em A e com aplicação de falsa-cor em B para o município de São João-PE.

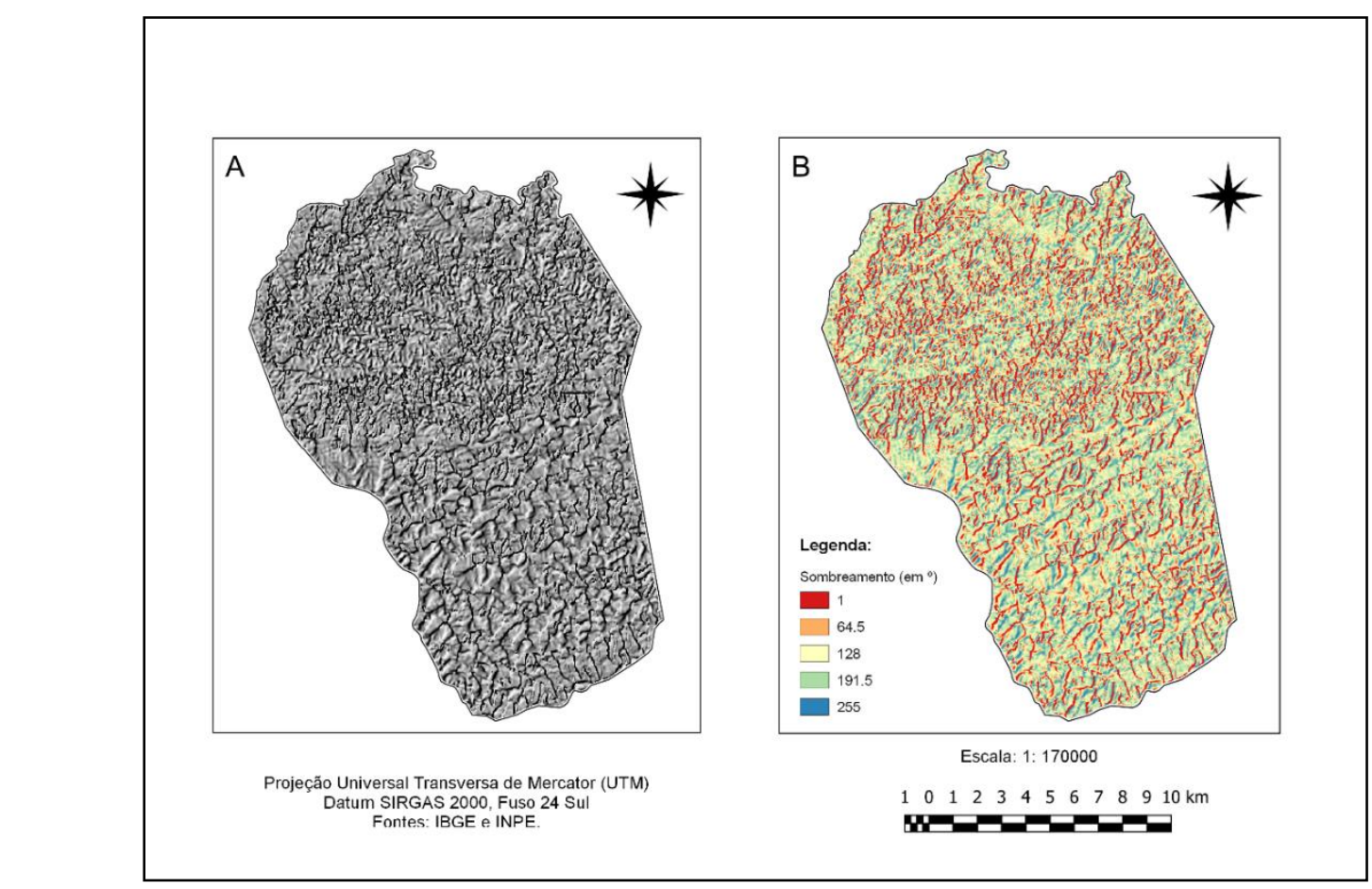

Fonte: Elaborado pelos Autores

\section{4 Índice de Rugosidade do Terreno (I.R.T.)}

De acordo com Bertol et al. (2006), a rugosidade pode ser entendida como a distribuição espacial das ondulações do terreno, ou seja, as variações de altura nas microelevações e de profundidade das microdepressões superficiais. Segundo Riley et al. (1999), o Índice de Rugosidade do Terreno (I.R.T.), no software QGIS, é calculado pela soma da mudança de elevação (em metros) entre uma célula (pixel) central e as oitos células vizinhas numa grade de $3 \times 3$, onde para cada célula em toda sua extensão área de estudo e os índices obtidos revelam claramente a heterogeneidade do terreno.

Na Figura 6A apresenta o índice de rugosidade do terreno (I.R.T.) em condição natural e em 6B, após aplicação de um gradiente espectral (blues), é possível perceber que o relevo propicia uma distribuição topográfica bem homogênea, superficialmente, resultando numa diminuição da erosão hídrica provocada pelas águas das chuvas em áreas susceptível, como por exemplo, solo exposto ou áreas cultivadas com poucas técnicas de conservação do solo (plantios 
em curvas de nível, terraceamentos, etc.).

Figura 6.

Mapas do Índice de Rugosidade do Terreno (I.R.T.), original em A e com aplicação de falsacor em B para o município de São João-PE.

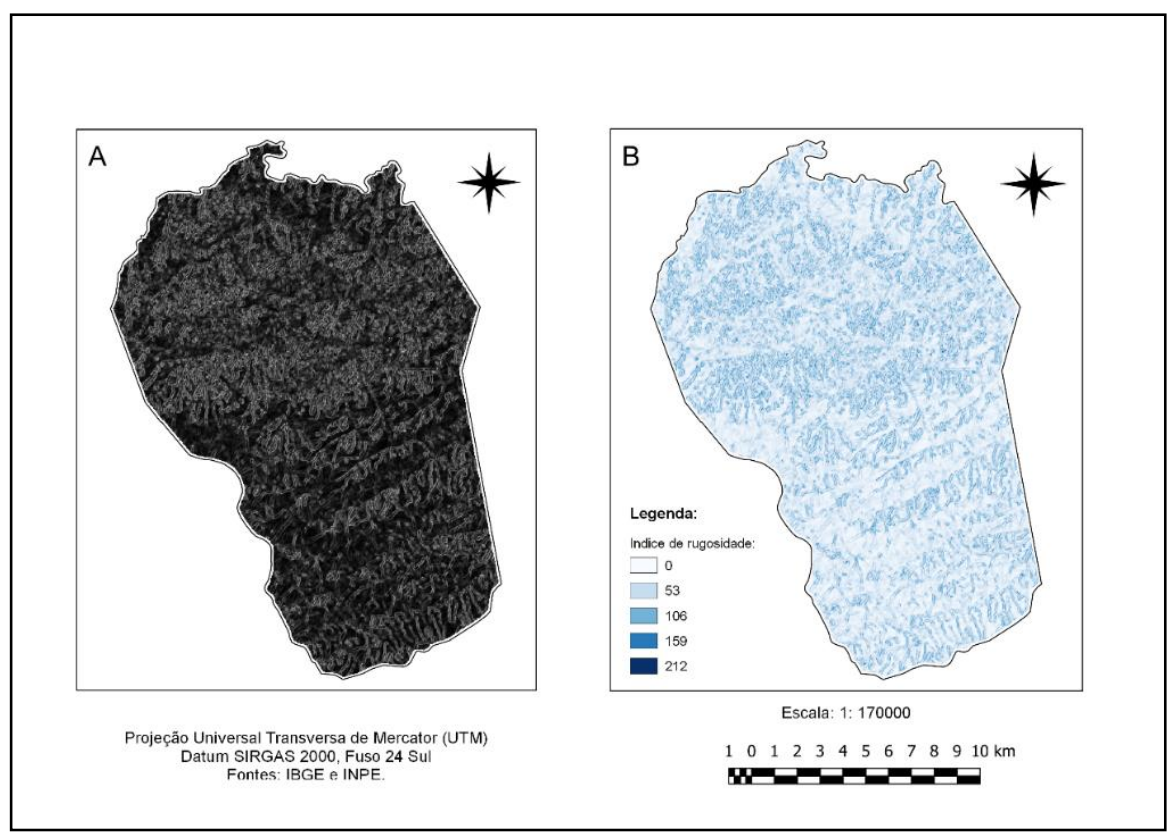

Fonte: Elaborado pelos Autores

O Índice de Rugosidade do Terreno támbém é muito usado para identificar áreas com tendências a erosividade hídrica em situações pontuais em função de eventos pluviométricos ao longo do tempo.

\section{CONCLUSÕES}

A partir do resultado apresentado na tabela e mapas temáticos, pode-se concluir que o município de São João-PE possui características de relevo que favorecem a condução de culturas agrícolas, sendo o relevo do local, ideal para aplicação de práticas como mecanização e irrigação. 


\section{REFERÊNCIAS}

Andrade, C.L.T, \& Brito, R. A. L. (2006). Métodos de irrigação e quimigação. Brasília, DF: Embrapa Milho e Sorgo - Circular Técnica. https://ainfo.cnptia.embrapa.br/digital/bitstream/CNPMS/19630/1/Circ_86.pdf

Barbieri, A., Gramacho dos Santos, H., Oliveira, I. E. A, \& Gomes, M. F. (2012). Elaboração de mapas temáticos no Quantum GIS. Brasília,DF: Instituto Nacional de Colonização e Reforma Agrária.

http://www.incra.gov.br/pt/media/servicos/publicacao/manuais_e_procedimentos/Apo stila_QGIS_INCRA_5a_versao.pdf

Bergamo, E. P., \& Almeida, J. A. P. (2006, setembro). A importância da geomorfologia para o planejamento ambiental: Um estudo do município de Fartura/SP. Anais do Simpósio Nacional de Geomorfologia, International Association of Geomorphologists - IAG, Goiânia, GO, Brasil, 6.

Bertol, I., Amaral, A. J., Vázquez, E. V., González, A. P., Barbosa, F. T., \& Brignoni, L. F. (2006). Relações da rugosidade superficial do solo com o volume de chuva e com a estabilidade de agregados em água. Revista Brasileira de Ciência do Solo, 3(3), 543553.

Bossle, R. C. (2015). QGIS e geoprocessamento na prática (1a ed.). São José dos Pinhais: Íthala.

Brito, J. L. S., Lima, S. D. C., Shiki, S., \& Moreira, M. R. (1998). Uso do Geoprocessamento na estimativa da perda de solos por erosão laminar em Irai de Minas-MG. Anais Simpósio Brasileiro De Sensoriamento Remoto (SBSR), Santos, SP, Brasil, 9.

Morisson, V. M., \& Rossetti, F. D. (2012). Topodata: Brazilian full coverage refinement of SRTM data. Applied Geography, 32(2), 300-309.

Empresa Brasileira de Pesquisa Agropecuária. (1979). Serviço nacional de levantamento e conservação de solos. Manual de métodos de análise de solo. Rio de Janeiro.

Gomes, D. D. M., Lima, D. R. M., Veríssimo, C. U. V., \& Duarte, C. R. (2016). Mapeamento e caracterização dos sistemas ambientais da bacia hidrográfica do Rio MundaúPE/AL. Caderno de Geografia, 26(2), 272-299.

Höfig, P., \& Araujo-Junior, C. F. (2015). Classes de declividade do terreno e potencial para mecanização no Estado do Paraná. Coffee Science, 10(2), 195 - 203.

Instituto Brasileiro de Geografia e Estatística. (2016). Cidades. http://cidades.ibge.gov.br/painel/painel.php?codmun=261320.

Malinovski, R. A., Malinovski, R. A., \& Malinovski, J. R. (2006, mai./ago). Análise das variáveis de influência na produtividade das máquinas de colheita de madeira em função das características físicas do terreno, do povoamento e planejamento operacional florestal. Curitiba, PR. Revista Floresta, 36(2), 169-182. 

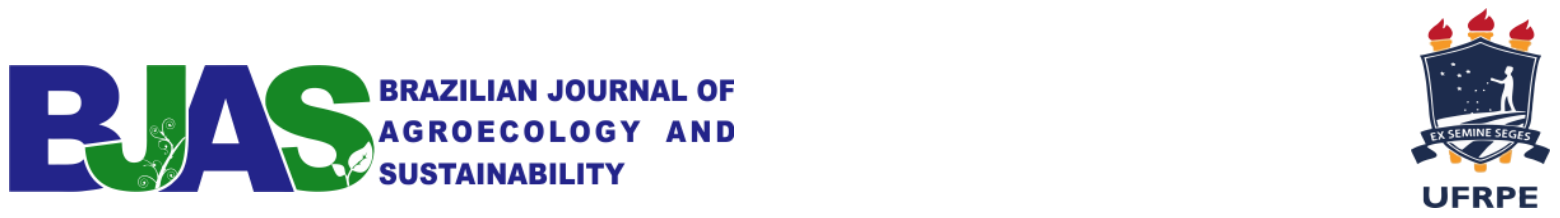

Minella, J. P. G., \& Merten, G. H. (2012). Índices topográficos aplicados à modelagem agrícola e ambiental. Ciência Rural, 42(9), 1575-1582.

QGIS Development Team (2020). QGIS Geographic Information System. Open Source Geospatial Foundation. http://qgis.osgeo.org.

Riley, S. J., Gloria, S. D. de, \& Elliot, R. (1999). Index that quantifies topographic heterogeneity. Intermountain Journal of sciences, 5(1-4), 23-27.

Silveira, G. R. P., Campos, S., Gonçalves, A. K., Barros, Z. X., \& Pollo, R. A. (2015). Geoprocessamento aplicado na espacialização da capacidade de uso do solo em uma área de importância agrícola. Energia na Agricultura, 30(4), 363-371.

Silva, F., Silva, M., Barros, A., Santos, J., Silva, A., Cavalcanti, A., ... \& Souza Neto, N. C. (2001). Zoneamento agroecológico de Pernambuco - Zape. Recife: Embrapa SolosUnidade de Execução de Pesquisa e Desenvolvimento (UEP). 